\title{
Seasonal Variation of Drug Prescription Rate for Overactive Bladder in Men Based on National Health Insurance Claims Data,
} 2012-2016

\author{
Jong Won Kim ${ }^{1}$, Hyun Kyu Ahn' ${ }^{1}$, Jongcheol Ko ${ }^{1}$, Dongu Lee ${ }^{1}$, Jee Soo Ha ${ }^{1}$, Jae Hwan Kim², So Jeong Park², Kang Su Cho ${ }^{1}$ \\ ${ }^{1}$ Department of Urology, Gangnam Severance Hospital, Yonsei University College of Medicine, Seoul, Korea \\ ${ }^{2}$ Data Science Team, Hanmi Pharmaceutical. Co. Ltd., Seoul, Korea
}

Purpose: Overactive bladder $(\mathrm{OAB})$ symptoms might be affected by weather, but only a few clinical studies have investigated this issue. We investigated seasonal variations in OAB-drug prescription rate (DPR) in men using nationwide claims data in Korea.

Methods: A total of 2,824,140 men aged over 18 years were included from the Health Insurance Review and Assessment service - National Patient Sample data between 2012 and 2016. Depending on the monthly average temperature, the seasons were divided into 3 groups, namely, hot (June, July, August, and September), intermediate (April, May, October, and November), and cold (January, February, March, and December) seasons. OAB-DPR was estimated using the claims data, and differences in its rate were examined among the 3 seasonal groups.

Results: The overall OAB-DPR was $1.97 \%$ (55,574 of 2,824,140). The OAB-DPR were $0.38 \%, 0.63 \%, 0.92 \%, 1.74 \%, 4.18 \%$, $7.55 \%$, and $9.69 \%$ in the age groups of under $30,30 \mathrm{~s}, 40 \mathrm{~s}, 50 \mathrm{~s}, 60 \mathrm{~s}, 70 \mathrm{~s}$, and over 80 years, respectively; thus, the prescription rate increased with age $(\mathrm{P}<0.001)$, with a steeper increase after 60 years of age. OAB-DPR was $1.02 \%$ in the hot season, $1.19 \%$ in the intermediate season, and $1.27 \%$ in the cold season, with significant differences among the 3 seasonal groups $(\mathrm{P}<0.001)$. These seasonal variations persisted in the subgroup analysis in each age decade $(\mathrm{P}<0.001)$.

Conclusions: OAB-DPR varied with seasons and was significantly higher in the cold season than in the hot season, suggesting that cold weather may affect development and aggravation of OAB symptoms in men.

Keywords: Men; Seasons; Urinary bladder, Overactive

- Research Ethics: The present study protocol was reviewed and approved by the Institutional Review Board (IRB) of Gangnam Severance Hospital (IRB No. 3-2019-0340). Informed consent was waived by the IRB.

- Conflict of Interest: Mr. Jae Hwan Kim and Ms. So Jeong Park are researchers of the Hanmi Pharmaceutical Co. Ltd., Seoul, Korea, but they made no influence on this work in relation with the company or its products. Other authors have no potential conflicts of interest to disclose.

\section{INTRODUCTION}

Overactive bladder $(\mathrm{OAB})$ is a prevalent cause of lower urinary tract symptoms (LUTS) defined as a syndrome of bladder storage function and characterized by a cluster of symptoms in- cluding urinary urgency, frequency, and nocturia with or without urinary incontinence [1]. Symptoms of OAB may have a detrimental impact on patients' quality of life (QoL) and could lead to emotional distress, depression, anxiety, and sleep disturbances [2]. Multiple urological and nonurological risk factors
Corresponding author: Kang Su Cho (iD https://orcid.org/0000-0002-3500-8833 Department of Urology, Gangnam Severance Hospital, Yonsei University College of Medicine, 211 Eonju-ro, Gangnam-gu, Seoul 06273, Korea E-mail: kscho99@yuhs.ac

Submitted: May 12, 2020 / Accepted after revision: July 18, 2020
This is an Open Access article distributed under the terms of the Creative Commons Attribution Non-Commercial License (https://creativecommons.org/licenses/by-nc/4.0/) which permits unrestricted non-commercial use, distribution, and reproduction in any medium, provided the original work is properly cited. 
are associated with the development of $\mathrm{OAB}$, such as age, obesity, cognitive disorders, metabolic syndrome, neurologic disorders, and benign prostatic hyperplasia (BPH) [3].

There is also a widely held perception that LUTS vary in severity with seasonal changes, and, in particular, that they worsen in cold weather. According to the 5-year BPH patient-based dataset (2008-2012) of National Health Insurance in Korea, seasonal variations of visiting hospital patients are seen between summer and winter [4]. Several studies have addressed the associations between seasonal variations and LUTS. Yoshimura et al. [5] revealed that winter is an independent risk factor for urinary frequency, urgency, and nocturia. Choi et al. [6] also reported that seasonal variations are meaningfully associated with LUTS, particularly storage symptoms. Kobayashi et al. [7] demonstrated a significant seasonal difference in nocturia only, which showed a higher score in winter; however, no seasonal difference was seen in uroflowmetric parameters. However, Cartwright et al. [8] reported no significant variation in the urinary symptom scores or uroflowmetric parameters with changes in season. Watanabe et al. [9] also reported no seasonal differences in the urinary symptom scores, although maximum flow rate (Qmax) could be influenced by seasonal changes. On the other hand, Tae et al. [10] demonstrated that female OAB symptoms might be worse during cold season than in other seasons. As seen in the aforementioned studies, seasonal variation might be related to storage symptoms, but such a relationship remains controversial. To obtain robust evidence on this issue, we investigated seasonal variations in $\mathrm{OAB}$-drug prescription rate (DPR) in men using nationwide claims data.

\section{MATERIALS AND METHODS}

\section{Data sources and Study Sample}

In South Korea, the National Health Insurance is a universal health coverage system that covers approximately $100 \%$ of Korean residents. The claims data of Health Insurance Review Agency (HIRA) is collected when healthcare service providers submit a claim to HIRA for reimbursement for a service that they provided to patients. The HIRA claims data represent 46 million patients each year, accounting for $90 \%$ of the total population in Korea. However, given the complexity and large volume of the dataset, its use is typically restricted to researchers. To resolve these limitations and increase the efficiency of data use, the HIRA developed patient sample data that passed validity tests performed by 5 different institutions [11]. Here, we used the national patient sample (NPS) of the HIRA claims data (HIRA-NPS) comprising randomized patients who used the National Health System at least once a year. This dataset passed validity tests performed by 5 different institutions and included 1.4 million patients overall per year (3\%) [11]. In this study, we used HIRA-NPS, 2012-2016, from which all men aged over 18 years were included.

\section{Climate Data and Seasonal Groups}

South Korea's location is $38^{\circ} \mathrm{N}, 127^{\circ} 30^{\prime} \mathrm{E}$; it is within a temperate climate region. Climate data were extracted from the Korea Meteorological Administration, and mean monthly temperatures were calculated (Table 1). According to the monthly average temperature, the seasons were divided into 3 groups: hot (June, July, August, and September), intermediate (April, May, October, and November), and cold (January, February, March, and December) seasons.

\section{Definition of $O A B$}

All available $\mathrm{OAB}$ drugs in Korea such as fesoterodine, imidafenacin, mirabegron, oxybutynin, propiverine, solifenacin, tolterodine, and trospium were included (Supplementary Table 1). OAB-DPR was calculated as the number of patients who were

Table 1. Monthly average temperature in South Korea from 2012 to 2016

\begin{tabular}{|c|c|c|c|c|c|c|c|c|c|c|c|c|}
\hline \multirow{2}{*}{ Year } & \multicolumn{12}{|c|}{ Temperature $\left({ }^{\circ} \mathrm{C}\right)$} \\
\hline & Jan & Feb & Mar & Apr & May & Jun & Jul & Aug & Sep & Oct & Nov & Dec \\
\hline 2012 & -1.2 & -0.8 & 5.7 & 12.6 & 18.3 & 22.1 & 25.5 & 26.4 & 20.2 & 14.3 & 6.6 & -1.7 \\
\hline 2013 & -2.1 & 0.7 & 6.6 & 10.3 & 17.8 & 22.6 & 26.3 & 27.3 & 21.2 & 15.4 & 7.1 & 1.5 \\
\hline 2014 & 0.5 & 2.5 & 7.7 & 13.4 & 18.4 & 21.9 & 25.1 & 23.8 & 20.9 & 14.8 & 8.8 & -0.5 \\
\hline 2015 & 0.5 & 2 & 6.7 & 12.7 & 18.6 & 21.7 & 24.4 & 25.2 & 20.5 & 15 & 10.1 & 3.5 \\
\hline 2016 & -0.9 & 1.7 & 7.2 & 13.8 & 18.6 & 22.3 & 25.4 & 26.7 & 21.6 & 15.8 & 7.8 & 3.1 \\
\hline Total $^{\text {a) }}$ & $-0.6 \pm 1.0$ & $1.2 \pm 1.2$ & $6.8 \pm 0.7$ & $12.6 \pm 1.2$ & $18.3 \pm 0.3$ & $22.1 \pm 0.3$ & $25.3 \pm 0.6$ & $25.9 \pm 1.2$ & $20.9 \pm 0.5$ & $15.6 \pm 0.5$ & $8.1 \pm 1.3$ & $1.2 \pm 2.0$ \\
\hline
\end{tabular}

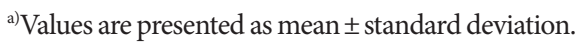


prescribed $\mathrm{OAB}$ drug among all patients during a certain period. The overall prescription rate was calculated, followed by the prescription rate according to the age and seasonal group.

\section{Statistical Analysis}

The chi-square test was used to investigate the association between OAB-DPR and seasonal variation. Logistic regression was used to assess the effect of each season on OAB-DPR, and odds ratios (ORs) and 95\% confidence intervals (CI) were calculated. $\mathrm{P}$ values of $\leq 0.05$ were considered statistically significant. All statistical analyses were performed using IBM SPSS Statistics ver. 25.0 (IBM Co., Armonk, NY, USA).

\section{RESULTS}

Of the total 7,223,663 people, 5,885,483 (81.48\%) were aged

\begin{tabular}{|c|}
\hline $\begin{array}{l}\begin{array}{l}\text { HIRA-NPS 2012-2016 } \\
\quad(\text { Total }=7,223,663)\end{array} \\
\text { HIRA-NPS } 2012(\mathrm{n}=1,422,492) \\
\text { HIRA-NPS } 2013(\mathrm{n}=1,431,445) \\
\text { HIRA-NPS } 2014(\mathrm{n}=1,447,441) \\
\text { HIRA-NPS } 2015(\mathrm{n}=1,454,252) \\
\text { HIRA-NPS } 2016(\mathrm{n}=1,468,033)\end{array}$ \\
\hline$\nabla$ \\
\hline $\begin{array}{l}\text { People who were over } 18 \text { years old } \\
\qquad \begin{array}{c}\text { (Total }=5,885,483 \text { ) } \\
\mathrm{n}=1,141,343 \text { in } 2012 \\
\mathrm{n}=1,158,175 \text { in } 2013 \\
\mathrm{n}=1,180,128 \text { in } 2014 \\
\mathrm{n}=1,193,194 \text { in } 2015 \\
\mathrm{n}=1,212,643 \text { in } 2016\end{array}\end{array}$ \\
\hline$\nabla$ \\
\hline $\begin{array}{l}\text { People who were men } \\
\text { (Total }=2,824,140) \\
\mathrm{n}=554,914 \text { in } 2012 \\
\mathrm{n}=554,081 \text { in } 2013 \\
\mathrm{n}=566,844 \text { in } 2014 \\
\mathrm{n}=573,688 \text { in } 2015 \\
\mathrm{n}=584,613 \text { in } 2016\end{array}$ \\
\hline$\nabla$ \\
\hline $\begin{array}{l}\text { People prescribed OAB medication } \\
\begin{array}{c}\text { (Total }=55,574) \\
\mathrm{n}=9,923 \text { in } 2012 \\
\mathrm{n}=10,260 \text { in } 2013 \\
\mathrm{n}=10,501 \text { in } 2014 \\
\mathrm{n}=11,376 \text { in } 2015 \\
\mathrm{n}=13,514 \text { in } 2016\end{array}\end{array}$ \\
\hline
\end{tabular}

Fig. 1. Case extraction diagram. HIRA, Health Insurance Review and Assessment Service; NPS, National Patient Sample; $\mathrm{OAB}$, overactive bladder. over 18 years. Among them, 2,824,158 (47.99\%) were men, and their mean age was $45.8 \pm 16.4$. A total of 55,574 men (1.97\%) were prescribed $\mathrm{OAB}$ drug once between 2012 and 2016, and their mean age was $62.4 \pm 15.3$ (Fig. 1). OAB-DPR by age group was $0.38 \%$ in those under 30 years, $0.63 \%$ in those in their 30 s, $0.92 \%$ in those in their 40 s, $1.74 \%$ in those in their 50 s, $4.18 \%$ in those in their 60s, $7.55 \%$ in those in their 70s, and $9.69 \%$ in those over 80 years (Table 2). Thus, the prescription rate increased with age, with a steeper increase after 60 years of age (Fig. 2).

In the present study, the seasons were divided into 3 groups as hot, intermediate, and cold seasons. The average temperatures were $23.6^{\circ} \mathrm{C} \pm 2.3^{\circ} \mathrm{C}$ in the hot season, $13.5^{\circ} \mathrm{C} \pm 4.0^{\circ} \mathrm{C}$ in the intermediate season, and $2.1^{\circ} \mathrm{C} \pm 3.2^{\circ} \mathrm{C}$ in the cold season. There were significant differences in OAB-DPR among the seasonal groups, with the prescription rate being $1.02 \%$ (reference) in the hot season, $1.19 \%$ (OR, 1.170; 95\% CI, 1.152-1.189) in the intermediate season, and 1.27\% (OR, 1.244; 95\% CI, 1.2251.264) in the cold season $(\mathrm{P}<0.001)$ (Table 3$)$. These seasonal variations persisted in the subgroup analysis of age decades $(\mathrm{P}<0.001)$ (Table 3).

\section{DISCUSSION}

Seasons of the year exerts an influence on certain disease conditions, such as coronary heart disease, cerebrovascular disease, and respiratory disease [12-14]. Our study demonstrated that OAB-DPR also varies among seasons: Specifically, it was significantly higher in the cold season than in the hot season, suggesting that cold weather may develop and aggravate $\mathrm{OAB}$ symptoms in men. This seasonal variation was consistently ob-

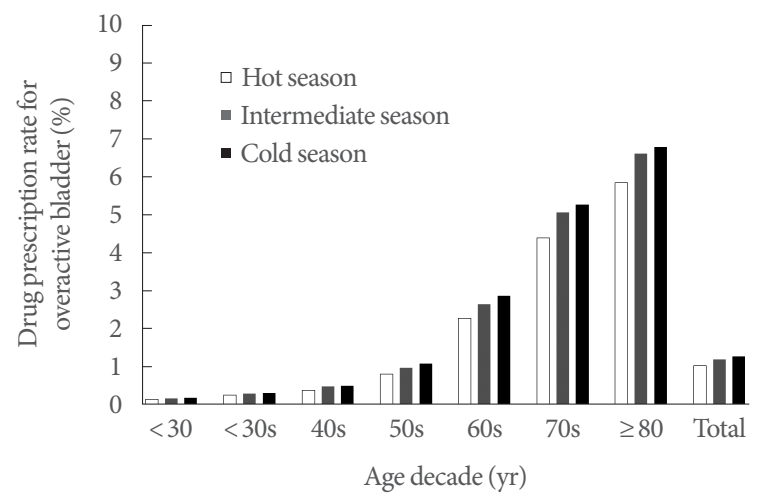

Fig. 2. Drug prescription rate for overactive bladder in men according to seasons in each age decade. 
Table 2. Drug prescription rate for $\mathrm{OAB}$ according to age decades

\begin{tabular}{|c|c|c|c|c|c|c|c|c|}
\hline \multirow{2}{*}{ Age (yr) } & \multirow{2}{*}{ Total patients } & \multirow{2}{*}{ Patient with $\mathrm{OAB}(\%)$} & \multicolumn{6}{|c|}{ Chi-square value } \\
\hline & & & $<30$ & $30 \mathrm{~s}$ & $40 \mathrm{~s}$ & $50 \mathrm{~s}$ & $60 \mathrm{~s}$ & $70 \mathrm{~s}$ \\
\hline$<30$ & 542,804 & $2,043(0.38)$ & & & & & & \\
\hline $30-39$ & 529,636 & $3,332(0.63)$ & $339.9^{\star * *}$ & & & & & \\
\hline $40-49$ & 593,346 & $5,476(0.92)$ & $1,271.3^{* * *}$ & $310.4^{* * *}$ & & & & \\
\hline $50-59$ & 563,157 & $9,782(1.74)$ & $4,837.4^{* * *}$ & $2,825.5^{* * *}$ & $1,470.8^{* * *}$ & & & \\
\hline $60-69$ & 335,422 & $14,025(4.18)$ & $16,710.3^{* * *}$ & $13,179.2^{* * *}$ & $11,067.9^{* * *}$ & $4,869 \cdot 6^{* * *}$ & & \\
\hline $70-79$ & 199,064 & $15,036(7.55)$ & $33,355.8^{\star * \star}$ & $28,231.9^{* * *}$ & $25,987.7^{\star * \star}$ & $15,795.5^{\star * *}$ & $2,762.7^{* * *}$ & \\
\hline$\geq 80$ & 60,711 & $5,880(9.69)$ & $36,521.8^{* * *}$ & $29,080.7^{\star * *}$ & $24,785.4^{\star * *}$ & $14,146.0^{\star * *}$ & $3,263 \cdot 1^{* * *}$ & $285.6^{* * *}$ \\
\hline
\end{tabular}

$\mathrm{OAB}$, overactive bladder.

${ }^{* * *} \mathrm{P}<0.001$ by Pearson chi-square test.

Table 3. Drug prescription rate for $\mathrm{OAB}$ according to the seasonal groups and age decades

\begin{tabular}{|c|c|c|c|c|c|c|}
\hline \multirow{2}{*}{ Age } & \multirow{2}{*}{ Total patients } & \multirow{2}{*}{ Season } & \multirow{2}{*}{ Patients with OAB (\%) } & \multicolumn{3}{|c|}{ Logistic regression analysis } \\
\hline & & & & Odd ratio & $95 \% \mathrm{CI}$ & P-value \\
\hline \multirow[t]{3}{*}{ Total } & $2,824,141$ & Hot & $28,849(1.02)$ & Reference & & $<0.001$ \\
\hline & & Intermediate & $33,698(1.19)$ & 1.170 & $1.152-1.189$ & \\
\hline & & Cold & $35,802(1.27)$ & 1.244 & $1.225-1.264$ & \\
\hline \multirow[t]{3}{*}{$<30$} & 542,804 & Hot & $754(0.14)$ & Reference & & $<0.001$ \\
\hline & & Intermediate & $883(0.16)$ & 1.171 & $1.063-1.291$ & \\
\hline & & Cold & $975(0.18)$ & 1.294 & $1.176-1.423$ & \\
\hline \multirow[t]{3}{*}{$30 \mathrm{~s}$} & 529,636 & Hot & $1,349(0.25)$ & Reference & & $<0.001$ \\
\hline & & Intermediate & $1,549(0.29)$ & 1.149 & $1.068-1.236$ & \\
\hline & & Cold & $1,597(0.30)$ & 1.184 & $1.101-1.274$ & \\
\hline \multirow[t]{3}{*}{$40 \mathrm{~s}$} & 593,346 & Hot & $2,258(0.38)$ & Reference & & $<0.001$ \\
\hline & & Intermediate & $2,820(0.48)$ & 1.250 & $1.183-1.321$ & \\
\hline & & Cold & $2,944(0.50)$ & 1.305 & $1.236-1.379$ & \\
\hline \multirow[t]{3}{*}{$50 \mathrm{~s}$} & 563,157 & Hot & $4,582(0.81)$ & Reference & & $<0.001$ \\
\hline & & Intermediate & $5,494(0.98)$ & 1.201 & $1.155-1.249$ & \\
\hline & & Cold & $6,090(1.08)$ & 1.333 & $1.282-1.385$ & \\
\hline \multirow[t]{3}{*}{$60 \mathrm{~s}$} & 335,422 & Hot & $7,628(2.27)$ & Reference & & $<0.001$ \\
\hline & & Intermediate & $8,859(2.64)$ & 1.166 & $1.130-1.202$ & \\
\hline & & Cold & $9,588(2.86)$ & 1.265 & $1.227-1.304$ & \\
\hline \multirow[t]{3}{*}{$70 \mathrm{~s}$} & 199,064 & Hot & $8,732(4.39)$ & Reference & & $<0.001$ \\
\hline & & Intermediate & $10,082(5.06)$ & 1.163 & $1.129-1.197$ & \\
\hline & & Cold & $10,494(5.27)$ & 1.213 & $1.178-1.249$ & \\
\hline \multirow[t]{3}{*}{$\geq 80$} & 60,711 & Hot & $3,546(5.84)$ & Reference & & $<0.001$ \\
\hline & & Intermediate & $4,011(6.61)$ & 1.140 & $1.088-1.195$ & \\
\hline & & Cold & $4,114(6.78)$ & 1.172 & $1.119-1.227$ & \\
\hline
\end{tabular}

$\mathrm{OAB}$, overactive bladder; $\mathrm{CI}$, confidence interval.

served in each age group. To the best of our knowledge, our study is the first report to investigate the relationship between seasonal variation and $\mathrm{OAB}-\mathrm{DPR}$ using a nationwide dataset.
The presumptive explanation of this observation is as follows: the first is the response of the muscles to the cold stress. Cold stress increases sympathetic activity, which stimulates smooth 


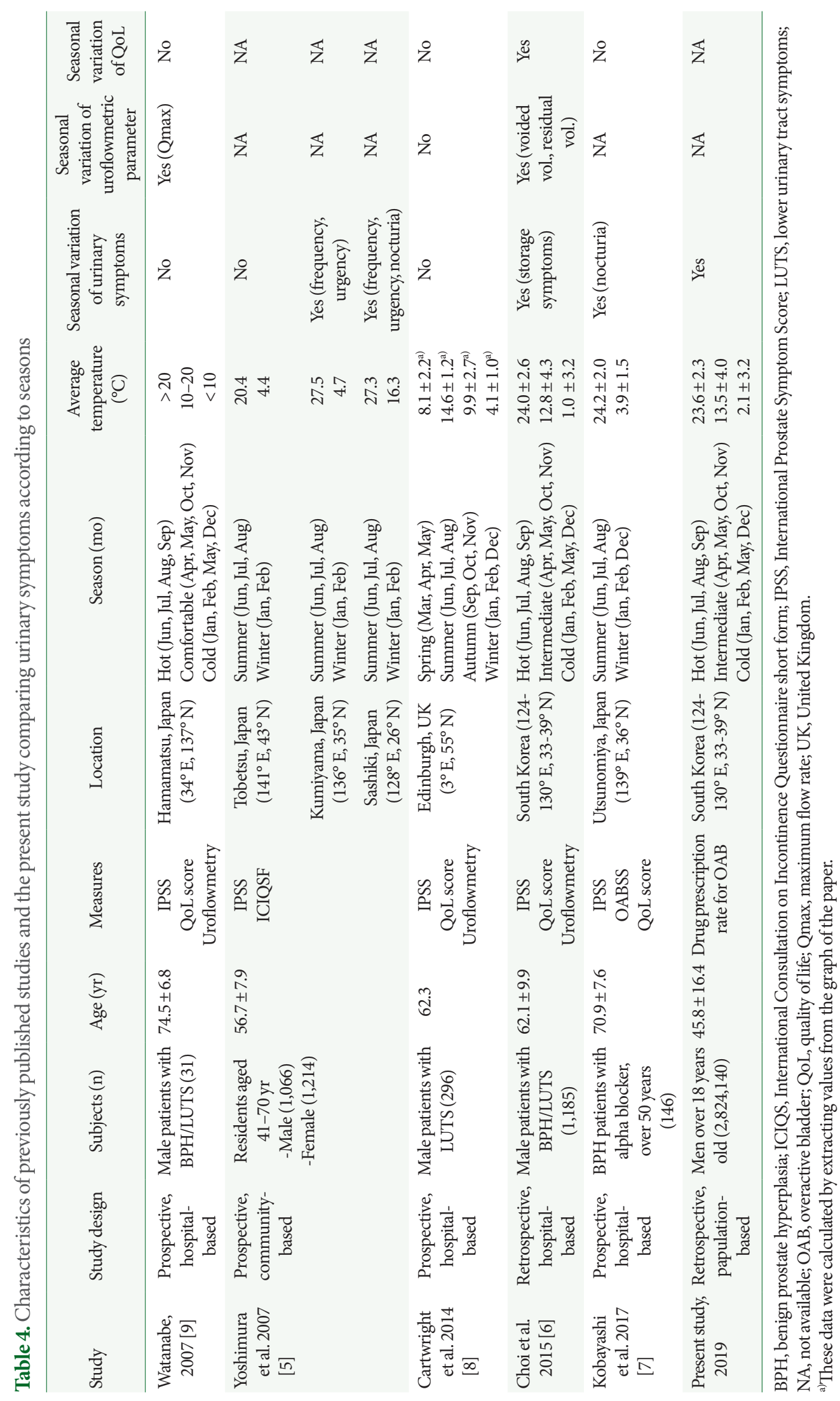


muscle contraction in the prostate, and induces detrusor overactivity, which decreases voiding interval and volume $[15,16]$. The second is the change in diuresis with temperature. Diuresis is reduced by insensible fluid loss from sweating at high temperatures [17]. On the contrary, cold stress not only provokes peripheral vasoconstriction, which inhibits vasopressin secretion and leads to diuresis [18], but also stimulates the secretion of plasma atrial natriuretic peptide, which enhances diuresis [19]. The third is seasonal variation in vitamin D levels. Increasing evidence suggests that vitamin D deficiency or insufficiency is associated with LUTS [20]. Vitamin D status was found to be an independent significant predictor of $\mathrm{OAB}$, with an increase of OAB risk by 44 times in patients with severe vitamin D deficiency [21]. The incidence of vitamin D deficiency was significantly higher during the winter than the summer $[22,23]$. These results suggest that seasonal changes in vitamin $D$ influence seasonal $\mathrm{OAB}$ development.

In previous studies, seasonal variation was more pronounced in storage symptoms than in voiding symptoms (Table 4) [5-7]. The Japanese Urological Association recommends conservative treatment in which men with LUTS avoid exposing their lower body to cold temperatures [24]. A large retrospective study by Choi et al. [6] demonstrated that symptom severity as measured using the International Prostate Symptom Score (IPSS) was worse in the cold season group than in the hot season group. Storage symptom scores were significantly worse in the cold, and the QoL score showed a significant difference between the cold and hot seasons. In uroflowmetric parameters, voided volume and postvoid residue exhibited a significant seasonal change, but there was no significant difference in Qmax. Kobayashi et al. [7] announced that nocturia had seasonal variation in patients with $\mathrm{BPH}$; however, there were no seasonal variation in the other IPSS categories and uroflowmetric parameters. Yoshimura et al. [5] performed a large communitybased questionnaire study in Japan including 3 towns (Tobetsu at higher latitude $\left[43^{\circ} \mathrm{N}\right]$, Kumiyama at middle latitude $\left[35^{\circ} \mathrm{N}\right]$, and Sashiki at lower latitude $\left.\left[26^{\circ} \mathrm{N}\right]\right)$ and reported that 3 storage symptoms (frequency, urgency, and nocturia) demonstrated significant differences between summer and winter; such a difference was observed in relatively low latitude areas (Kumiyama and Sashiki) but not in higher latitude areas (Tobetsu). Likewise, a prospective study performed in Edinburgh, United Kingdom, showed no seasonal variation in urinary symptoms and uroflowmetric parameters [8]. Edinburgh is located at a relatively high latitude $\left(55^{\circ} \mathrm{N}\right)$. These findings suggested that climate can influence seasonal variations in LUTS. Watanabe et al. [9] also explored changes in IPSS and uroflowmetric parameters associated with seasonal changes in 31 men with LUTS and found no significant seasonal change in IPSS or QoL but reported that Qmax exhibited a significant seasonal change, unlikely to expectation, being higher in the winter than in the summer. The authors mentioned that indoor temperatures in the winter were higher than outdoor temperatures due to central heating, whereas indoor temperatures in the summer were lower due to air-conditioning. However, the number of subjects was too small to draw concrete results.

Shim et al. [4] conducted a cross-sectional survey to investigate the association between daily temperature and LUTS in men and found that it was not affected by average daily temperature but was affected by diurnal temperature variations. Goriunov and Davidov [25] reported that the frequency of acute urinary retention (AUR) was affected by day-to-day temperature fluctuations $\left(\geq 5^{\circ} \mathrm{C}\right)$ or a change in the atmospheric pressure ( $\geq 9 \mathrm{hPa}$ ) and humidity ( $\geq 20 \%)$. They studied the effect of daily temperature variations on LUTS or AUR and found that daily temperature variations did not reflect seasonal variations in weather because seasonal changes include not only changes in temperature but also those in other climatic factors such as humidity and total sunshine. Keller at al. [26] demonstrated that AUR was negatively correlated with ambient temperature, relative humidity, and rainfall and significantly correlated with hours of sunshine and atmospheric pressure.

In a large cross-sectional, population-based study in Korea, questionnaire-based $\mathrm{OAB}$ prevalence was $2.9 \%$ [27], but most studies reported $10 \%-20 \%$ OAB prevalence $[2,28,29]$. Such discrepancy can be explained by the differences in OAB definition, survey questionnaires for $\mathrm{OAB}$, survey methods, and characteristics of the study populations. In our study, OAB-DPR was $1.97 \%$. The prescription rate may differ from those prevalence rates surveyed, because our study was based on OAB-DPR, not on the diagnosis of OAB. This might be a limitation of our study, but it suggests that a significant number of patients with $\mathrm{OAB}$ symptoms require medical help. This study also had other limitations. First, since HIRA-NPS is not longitudinal database, it was impossible to obtain prior history of $\mathrm{OAB}$ diagnosis or $\mathrm{OAB}$ drug medication. This study did not include detailed clinical data on other comorbidities that could affect OAB. Second, the present study was based on OAB-DPR, not on the diagnosis of OAB. Third, the study year might be an important variable, but there was no difference in seasonal variation for each year 
(data not shown). Fourth, we performed the analysis using only the monthly average temperature of the country instead of using the temperatures corresponding to actual locations of the patients' residences, although the range of latitude is relatively small in Korea. Despite these limitations, our study demonstrated that seasonal variation affects OAB-DPR, suggesting that seasonal changes can affect development of OAB symptoms that require medication.

In conclusions, OAB-DPR was affected by seasons, being significantly higher in the cold season than in the hot season. This suggests that cold weather may affect development and aggravation of $\mathrm{OAB}$ symptoms in men. Therefore, it may be helpful to consider seasonal changes when managing patients with OAB symptoms.

\section{SUPPLEMENTARY MATERIAL}

Supplementary Table 1 can be found via https://doi.org/10.5213/ inj.2040030.015.

\section{REFERENCES}

1. Trinh H, Irish V, Diaz M, Atiemo H. Outcomes of intradetrusor onabotulinum toxin A therapy in overactive bladder refractory to sacral neuromodulation. Int Neurourol J 2019;23:226-33.

2. Stensland KD, Sluis B, Vance J, Schober JP, MacLachlan LS, Mourtzinos AP. Predictors of nerve stimulator success in patients with overactive bladder. Int Neurourol J 2018;22:206-11.

3. Son YJ, Kwon BE. Overactive bladder is a distress symptom in heart failure. Int Neurourol J 2018;22:77-82.

4. Shim SR, Kim JH, Won JH, Song ES, Song YS. Association between ambient temperature and lower urinary tract symptoms: a community-based survey. Int Braz J Urol 2016;42:521-30.

5. Yoshimura K, Kamoto T, Tsukamoto T, Oshiro K, Kinukawa N, Ogawa O. Seasonal alterations in nocturia and other storage symptoms in three Japanese communities. Urology 2007;69:864-70.

6. Choi HC, Kwon JK, Lee JY, Han JH, Jung HD, Cho KS. Seasonal variation of urinary symptoms in Korean men with lower urinary tract symptoms and benign prostatic hyperplasia. World J Mens Health 2015;33:81-7.

7. Kobayashi M, Nukui A, Kamai T. Seasonal changes in lower urinary tract symptoms in Japanese men with benign prostatic hyperplasia treated with alpha1-blockers. Int Neurourol J 2017;21:197203.

8. Cartwright R, Mariappan P, Turner KJ, Stewart LH, Rajan P. Is there seasonal variation in symptom severity, uroflowmetry and frequency-volume chart parameters in men with lower urinary tract symptoms? Scott Med J 2014;59:162-6.

9. Watanabe T, Maruyama S, Maruyama Y, Kageyama S, Shinbo H, Otsuka A, et al. Seasonal changes in symptom score and uroflowmetry in patients with lower urinary tract symptoms. Scand J Urol Nephrol 2007;41:521-6.

10. Tae BS, Park TY, Jeon BJ, Chung H, Lee YH, Park JY, et al. Seasonal variation of overactive bladder symptoms in female patients. Int Neurourol J 2019;23:334-40.

11. Kim L, Kim JA, Kim S. A guide for the utilization of Health Insurance Review and Assessment Service National Patient Samples. Epidemiol Health 2014;36:e2014008.

12. Spencer FA, Goldberg RJ, Becker RC, Gore JM. Seasonal distribution of acute myocardial infarction in the second National Registry of Myocardial Infarction. J Am Coll Cardiol 1998;31:1226-33.

13. Inagawa T, Shibukawa M, Inokuchi F, Tokuda Y, Okada Y, Okada K. Primary intracerebral and aneurysmal subarachnoid hemorrhage in Izumo City, Japan. Part II: management and surgical outcome. J Neurosurg 2000;93:967-75.

14. Nakaji S, Parodi S, Fontana V, Umeda T, Suzuki K, Sakamoto J, et al. Seasonal changes in mortality rates from main causes of death in Japan (1970--1999). Eur J Epidemiol 2004;19:905-13.

15. Roehrborn CG, Schwinn DA. Alpha1-adrenergic receptors and their inhibitors in lower urinary tract symptoms and benign prostatic hyperplasia. J Urol 2004;171:1029-35.

16. LeBlanc J. Mechanisms of adaptation to cold. Int J Sports Med 1992;13 Suppl 1:S169-72.

17. Kohn D, Flatau E. Points: why does cold weather cause frequency of micturition in some elderly people? Br Med J 1980;281:875.

18. Stocks JM, Taylor NA, Tipton MJ, Greenleaf JE. Human physiological responses to cold exposure. Aviat Space Environ Med 2004;75: 444-57.

19. Hassi J, Rintamaki H, Ruskoaho H, Leppaluoto J, Vuolteenaho O. Plasma levels of endothelin-1 and atrial natriuretic peptide in men during a 2-hour stay in a cold room. Acta Physiol Scand 1991;142: 481-5.

20. Parker-Autry CY, Burgio KL, Richter HE. Vitamin D status: a review with implications for the pelvic floor. Int Urogynecol J 2012; 23:1517-26.

21. Abdul-Razzak KK, Alshogran OY, Altawalbeh SM, Al-Ghalayini IF, Al-Ghazo MA, Alazab RS, et al. Overactive bladder and associated psychological symptoms: a possible link to vitamin $\mathrm{D}$ and calcium. Neurourol Urodyn 2019;38:1160-7.

22. Sim MY, Kim SH, Kim KM. Seasonal variations and correlations 
between vitamin D and total testosterone levels. Korean J Fam Med 2017;38:270-5

23. Eloi M, Horvath DV, Szejnfeld VL, Ortega JC, Rocha DA, Szejnfeld $J$, et al. Vitamin D deficiency and seasonal variation over the years in Sao Paulo, Brazil. Osteoporos Int 2016;27:3449-56.

24. Homma Y, Araki I, Igawa Y, Ozono S, Gotoh M, Yamanishi T, et al. Clinical guideline for male lower urinary tract symptoms. Int J Urol 2009;16:775-90.

25. Goriunov VG, Davidov MI. [The effect of meteorological factors on the incidence of acute urinary retention]. Urol Nefrol (Mosk) 1996;(1):4-7. Russian.

26. Keller JJ, Lin CC, Chen CS, Chen YK, Lin HC. Monthly variation in acute urinary retention incidence among patients with benign prostatic enlargement in Taiwan. J Androl 2012;33:1239-44.

27. Kim SY, Bang W, Choi HG. Analysis of the prevalence and associated factors of overactive bladder in adult Korean men. PLoS One 2017;12:e0175641.

28. Milsom I, Abrams P, Cardozo L, Roberts RG, Thuroff J, Wein AJ. How widespread are the symptoms of an overactive bladder and how are they managed? A population-based prevalence study. BJU Int 2001;87:760-6.

29. Lee YS, Lee KS, Jung JH, Han DH, Oh SJ, Seo JT, et al. Prevalence of overactive bladder, urinary incontinence, and lower urinary tract symptoms: results of Korean EPIC study. World J Urol 2011;29:185-90. 